\title{
Summary of the workshop on methodologies for environmental public health tracking of air pollution effects
}

\author{
Thomas D. Matte • Aaron Cohen • Fred Dimmick • \\ Jonathan Samet • Jeremy Sarnat • Fuyuen Yip • \\ Nicholas Jones
}

Received: 19 August 2009 / Accepted: 7 October 2009/Published online: 31 December 2009

(C) The Author(s) 2009. This article is published with open access at Springerlink.com

\begin{abstract}
The US Centers for Disease Control and Prevention established the Environmental Public Health Tracking (EPHT) program to support state and local projects that characterize the impact of the environment on health. The projects involve compiling, linking, analyzing, and disseminating environmental and health surveillance information, thereby engaging stakeholders and guiding actions to improve public health. One of the EPHT objectives is to track the public health impact of ambient air pollution with analyses that are timely and relevant to state and local stakeholders. To address methodological issues relevant to this objective, in January 2008, government officials and researchers from the USA, Canada, and Europe gathered in Baltimore, Maryland for a 2-day workshop. Using commissioned papers and presentations on key methodological
\end{abstract}

The views expressed in this article are those of the authors and do not necessarily reflect the views of the Health Effects Institute (HEI) or its sponsors.

T. D. Matte $(\triangle)$

Division of Environmental Hazards and Health Effects,

National Center for Environmental Health,

US Centers for Disease Control and Prevention,

Atlanta, GA, USA

e-mail: tmatte@health.nyc.gov

\section{A. Cohen}

Health Effects Institute,

Boston, MA, USA

F. Dimmick

US Environmental Protection Agency,

National Exposure Research Laboratory,

Research Triangle Park, NC, USA

J. Samet

University of Southern California,

Los Angeles, CA, USA issues as well as examples of previous air pollution impact assessments, work group discussions produced a set of consensus recommendations for the EPHT program. These recommendations noted the need for data that will encourage local stakeholders to support continued progress in air pollution control. The limitations of using only local data for analyses were also noted. To improve local estimates of air pollution health impacts, methods were recommended that "borrow strength" from other evidence. An incremental approach to implementing such methods was recommended. The importance and difficulty of communicating uncertainties in local health impact assessments was emphasized, as was the need for coordination among different agencies conducting health impact assessments.

J. Sarnat

Emory University School of Public Health,

Atlanta, GA, USA

F. Yip

Air Pollution and Respiratory Health Branch,

National Center for Environmental Health,

US Centers for Disease Control and Prevention, Atlanta, GA, USA

N. Jones

Environmental Health Tracking Branch, National Center for Environmental Health, US Centers for Disease Control and Prevention, Atlanta, GA, USA 
Keywords Environmental exposure .

Population surveillance $\cdot$ Public health $\cdot$ Air pollution

\section{Introduction}

The mission of Centers for Disease Control and Prevention (CDC)'s Environmental Public Health Tracking (EPHT) program is "...to provide information from a nationwide network of integrated health and environmental data that drives actions to improve the health of communities,..." (CDC 2006). Consistent with this mission, a key objective of the EPHT program is tracking the public health burden of ambient air pollution with analyses that are timely and relevant to local stakeholders. To address methodological issues relevant to this objective, in January 2008 a 2-day workshop in Baltimore, Maryland, jointly organized and sponsored by Health Effects Institute, CDC, and US EPA, brought together representatives of state and national public health and environmental agencies and academic researchers from the USA, Canada, and Europe. Among the workshop participants were persons with expertise and experience in the development and application of statistical and epidemiologic tools for air pollution health impact assessment in both academic and policy settings in North America and in Europe (see Appendix 1).

Workshop participants were charged with producing recommendations for use at the state and local levels for communicating the results of the analyses to stakeholders. These recommendations would suggest ways to analyze linked air quality and health data and to estimate and track over time health impact indicators for two pollutants: fine particulate matter $\left(\mathrm{PM}_{2.5}\right)$ and ozone.

Specifically, the participants were asked to recommend:

1. Approaches for using analyses of state data to generate state and sub-state impact estimates for acute effects of air pollution;

2. Approaches for using current quantitative estimatesand to develop further estimates - of the relationship between air pollution exposure and health outcomes from the scientific literature, as well as ways to generate estimates of acute and chronic health impacts in local areas; and

3. Approaches for communicating to stakeholders the estimates and the limitations of those estimates.

In working papers commissioned before the workshop (Bachmann 2008; Fuentes 2009; Hubbell et al. 2009; Medina et al. 2009; Shin et al. 2009; Talbot et al. 2009; Wartenberg 2009; White 2009) and in workshop presentations, relevant work of the EPHT program was reviewed, previous health impact assessments were described, and methodological topics were discussed. The workshop participants then discussed key methodological issues and made recommendations regarding further development and application of indicators of the health effects of air pollution-specifically, indicators that would be suitable for public health tracking of air pollution impacts at the state and local level.

This paper summarizes the workshop discussions and recommendations for developing ongoing and consistent implementation of air pollution health impact assessments by state and local agencies.

\section{The need for timely and locally relevant information on the health effects related to air pollution}

Over the past 50 years, the USA has made considerable progress in reducing levels of health-damaging ambient air pollution, progress that has resulted in substantial public health benefits (US EPA 1997, 1999). Nevertheless, in some areas of the country, $\mathrm{PM}_{2.5}$ and ozone levels currently exceed National Ambient Air Quality Standards (US EPA 2008). In terms of increased mortality and morbidity, especially cardiovascular and respiratory disease, exposure to air pollution continues to affect the health of the US population (US EPA 2004a, b, 2005a, b, 2006, 2007).

While air quality improvements are projected to continue, increasing urban sprawl, traffic volume, and congestion may be slowing progress and threatening future gains, especially in some regions (Frumkin et al. 2004). At the same time, growing evidence points to the importance of health impacts associated with intra-urban gradients in ambient air pollution, particularly those related to traffic (Miller et al. 2007; Jerrett et al. 2005). Thus, future advances in public health protection will likely require improved understanding of those local pollution sources and potential control measures that impinge on state and local land use and transportation policy. The more such measures affect local stakeholders, the greater the need for local engagement in the process. Providing local stakeholders timely, understandable and locally relevant data on air pollution health impacts will be a necessary part of such engagement.

Environmental public health tracking has been defined as the "ongoing collection, integration, analysis and dissemination of data from environmental hazard monitoring, human exposure tracking, and health effects surveillance" (Meyer et al. 2006; Environmental Health Tracking Project Team 2000). Consistent with CDC's model of public health surveillance, the communication of findings to those with a "need to know" (Thacker and Berkelman 1988) is a key component. The tracking model broadly defines stakeholders who are targets of dissemination efforts to 
include policy makers, government and nongovernmental agencies, businesses, researchers, the media, and members of the public. Because the health effects of $\mathrm{PM}_{2.5}$ and ozone are well established, the EPHT program identifies ambient air pollution as a priority for tracking indicators of exposure and for health impact assessment. As a result of a collaboration between CDC, US EPA, and state EPHT programs, an infrastructure within the Environmental Public Health Tracking Network (EPHTN) is under development (Talbot et al. 2009; Boothe et al. 2005). This infrastructure will enable ongoing, periodic, and timely analyses of the health impacts of air pollution at the state and local levels and will address such questions as:

- What is the public health burden attributable to ambient $\mathrm{PM}_{2.5}$ and ozone levels?

- How does the burden vary within and between states?

- Is the burden changing over time, for example, in response to efforts to reduce air pollution levels and population exposure?

\section{Methodological challenges}

Estimating the health impacts of air pollutants is more complex than estimating some health impacts of certain environmental exposures. For example, acute carbon monoxide poisonings (which generally result from indoor, not ambient, exposures) can be diagnosed with specificity when compatible signs and symptoms occur in the presence of an elevated level of carboxyhemoglobin. The number and rate of such events can be tracked using hospital inpatient and emergency department administrative data. For the EPA's criteria air pollutants, generally, there is, unfortunately, no similarly straightforward way to track public health impacts. The most serious known health effects of exposure to air pollutants such as $\mathrm{PM}_{2.5}$ and ozone, both indicators of complex mixtures with no wellaccepted or easily measured specific biomarkers, involve morbidity and mortality from diseases of the cardiovascular and respiratory systems that have multiple other complex causes. Therefore, although the contribution of the diseases themselves to the overall burden of disease in a population can be estimated categorically by identifying individuals who meet pre-specified clinical criteria, the burden attributable to $\mathrm{PM}_{2.5}$ or ozone cannot be unambiguously identified and can only be estimated from statistical models.

While an extensive body of research has established causal links between exposure to these pollutants and human health, concentration-response (CR) relationships quantifying these links have, for a variety of reasons, been shown to vary among geographic areas and over time (Samet et al. 2000; Samet 2008; Katsouyanni et al. 2001; Hubbell et al. 2009). $\mathrm{PM}_{2.5}$ and ozone may serve in part as indicators of complex pollutant mixtures (White 2009), and variation in composition by space and time may alter the concentration/health impact relationship. Additional modifying factors include population susceptibility and local health care utilization, services, and recording practices. In addition to these relatively stable local differences, exceptional local weather events or emission sources, including forest or structural fires or construction demolition, may introduce within a local area different pollutant species or extreme pollutant levels. In addition, local interventions, including enhanced air quality alerts, land use and transportation changes, and control of local point sources may alter local air quality and affect human exposure and its relationship to health.

Although estimates from purely local analyses should in theory best reflect local modifiers of a CR function, "true" $\mathrm{CR}$ relationships at prevalent ambient air pollution levels are small relative to random error and potential bias affecting a single local study. Thus, estimates based on local data only may not accurately reflect the underlying CR relationship and may even give indications of either anomalous "protective" effects or implausibly large effect risk estimates. The methodological challenges stemming from use of local data are even greater for estimating time trends at the state and sub-state levels for air pollution's impact on health.

Communicating with stakeholders in a meaningful and complete way concerning the information gained from the EPHT analysis poses additional challenges, especially when attempting to set out clearly any uncertainties and their implications (IPCC 2005).

Previous health impact assessments of air pollution conducted in Europe, the USA, and Canada have grappled with these issues (Cohen et al. 2004; Le Tertre et al., 2005; USEPA 2005b; Burnett et al. 2005; Medina et al. 2009). Considering the lessons learned from these efforts, other relevant methodological work, and the context of EPHT programs based in state and local health departments, workshop participants developed the conclusions and recommendations summarized below. A full version of the workshop report and recommendations is available at http:// www.cdc.gov/nceh/tracking/default.htm.

\section{Major workshop conclusions and recommendations}

- Future progress in public health protection will likely require improved understanding of local air pollution sources and control measures that require the engagement of local stakeholders. By providing timely and 
locally relevant data on air pollution health impacts, the EPHTN can become a motivating factor in such engagement while making an important contribution to public health protection.

- Analyses of $\mathrm{PM}_{2.5}$ and ozone health impacts that use only air pollution and health data from a single geographic area are unlikely to provide robust estimates of the relation between air pollution and acute and chronic health effects, although such analyses may be appropriate for other research or for surveillance applications (Talbot et al. 2009). Therefore, when making such estimates, various methods of "borrowing strength" from other evidence are essential, especially when quantifying local public health impacts (Fuentes 2009).

- The EPHT program should incrementally develop tracking of air quality health impacts (Fig. 1).

- An initial goal should be the development, testing, and application of a methodology for local health impact assessment at selected locations and that methodology should use quantitative estimates of the concentrationresponse relationships between air pollution exposure and health outcomes from the scientific literature (Hubbell et al. 2009). Clear operational guidance for applying the method and communicating results should be provided.

- In the longer term, a network of EPHT programs should develop analyses that draw strength from pooled evidence across locations to produce cross-sectional estimates of local CR functions (Fuentes 2009). Once established, this type of network would enable longitudinal analyses that track impact over time, which may identify changes in $\mathrm{CR}$ functions attributable, for example, to changes in $\mathrm{PM}_{2.5}$ composition. Such

Confidence in/availability of local data

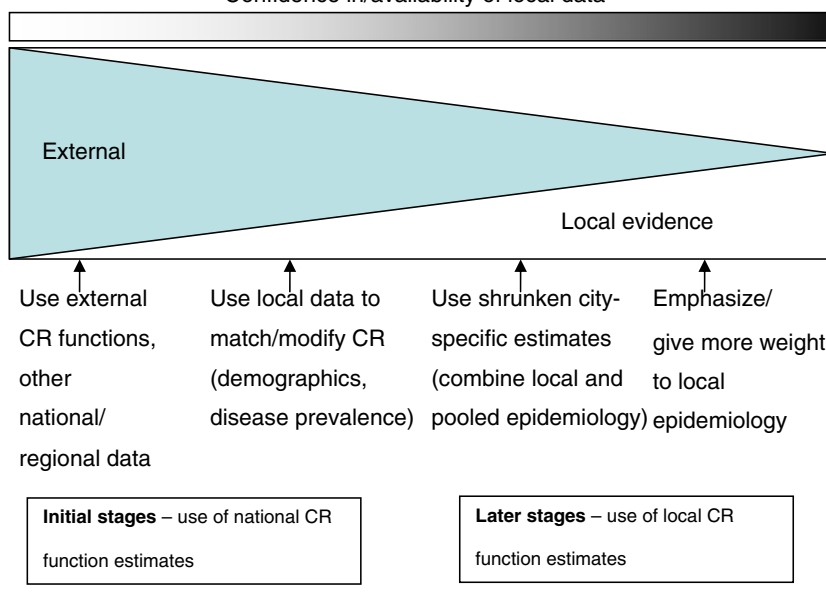

Fig. 1 Conceptual model for staged development of air pollution health impact assessment for environmental public health tracking analyses could support "accountability" measures (Shin et al. 2009; HEI Accountability Working Group 2003) of the effectiveness of local, regional, and national air quality management initiatives.

- Developing local CR function estimates that describe, at the state and sub-state levels, the relationship between air pollution exposure and health will initially require considerably more methodological groundwork, as discussed by Fuentes (2009), than will health impact assessments using published CR function estimates. In addition, this approach requires a process that ensures standard methods for data preparation and analysis across states while addressing the confidentiality requirements of data stewards in each state.

- The EPHT should review the current experience with regard to choice of air pollution health impact metrics (e.g., counts of attributable deaths and other adverse health outcomes vs. attributable impact on life expectancy or healthy life expectancy) and the way in which they are communicated, with the goals of (1) achieving consensus on the best approaches for the EPHTN and (2) identifying critical knowledge gaps that could be addressed with additional research or methods development. Currently, the scientific community has yet to resolve which metric(s) best quantify the impacts of air pollution and which are most meaningful to diverse stakeholders, including the public (McMichael et al. 1998; Rabl 2005; Brunekreef et al. 2007; Wartenberg 2009).

- A critical but challenging goal for EPHTN will be to provide a complete and straightforward account of the uncertainties in local air pollution health impact estimates. The CDC Environmental Public Health Tracking Program should review the current experience with regard to efforts to communicate uncertainty in estimates of health effects and health impact assessments of environmental hazards (e.g., IPCC 2005), with the goals of (1) achieving consensus on the best approaches for the EPHTN; (2) identifying critical knowledge gaps that could be addressed with additional research; and (3) supporting the overall transparency and credibility of the tracking network's results.

- Communication among different agencies conducting health impact assessments is also needed. Currently, in the USA, health impact assessments of exposure to air pollution are carried out by agencies at different levels, including US EPA, states, and municipalities. The tracking program should work with involved agencies to avoid, if possible, methodologic inconsistencies that could produce artifactual differences in impact estimates. A well-developed communication strat- 
egy regarding health effects and impacts of air pollution, coordinated with other relevant agencies such as US EPA, should be an integral part of the EPHT.

Open Access This article is distributed under the terms of the Creative Commons Attribution Noncommercial License which permits any noncommercial use, distribution, and reproduction in any medium, provided the original author(s) and source are credited.

\section{Appendix 1}

Workshop participants

Workshop on Methodologies for Environmental Public Health Tracking of Air Pollution Effects

January 15-16, 2008

Admiral Fell Inn

Baltimore, Maryland

Participant list

\section{Robert Altenburg}

Pennsylvania Department of Environmental Protection Policy Office

Harrisburg, PA

\section{H Ross Anderson}

Professor of Epidemiology and Public Health

Community Health Sciences

St. George's University of London

London, UK

\section{Steve Anderson}

Research Scientist

New Jersey Department of Environmental Protection

Trenton, NJ

John Bachmann (Work group chair)

Principal

Vision Air Consulting, LLC

Chapel Hill, NC

John Balmes (Work group chair)

Professor

University of California, Berkeley

and University of California, San Francisco

San Francisco, CA

\section{Richard Burnett}

Senior Research Scientist

Environmental Health Directorate Health Canada

Ottawa, Canada
Aaron Cohen (Steering committee member)

Principal Scientist

Health Effects Institute

Boston, MA

Fred Dimmick (Steering committee member)

Branch Chief

US Environmental Protection Agency

National Exposure Research Laboratory

Research Triangle Park, NC

\section{Francesca Dominici}

Professor

Department of Biostatistics

Johns Hopkins Bloomberg School of Public Health

Baltimore, MD

\section{Jerald Fagliano}

Program Manager

New Jersey Department of Health and Senior Services

Trenton, NJ

\section{Faye Floyd}

Public Health Advisor/Project Officer

US Centers for Disease Control and Prevention

National Center for Environmental Health

Environmental Health Tracking Branch

Atlanta, GA

\section{Montserrat Fuentes}

Associate Professor

Department of Statistics

North Carolina State University

Raleigh, NC

\section{Paul Garbe}

Branch Chief, Air Pollution and Respiratory Health Centers for Disease Control and Prevention National Center for Environmental Health Atlanta, GA

\section{Valerie Haley}

Research Scientist

New York State Department of Health

Troy, NY

\section{Lisa Hines}

Senior Health Communications Specialist

Environmental Health Tracking Branch

Centers for Disease Control and Prevention

Atlanta, GA 


\section{Bryan Hubbell}

Senior Advisor for Science and Policy Analysis

Health and Environmental Impacts Division

US Environmental Protection Agency

Research Triangle Park, NC

Nicholas Jones (Steering committee member; Work group rapporteur)

Team Lead Scientific Development

Environmental Health Tracking Branch

US Centers for Disease Control and Prevention

Atlanta, GA

\section{Michal Krzyzanowski}

Regional Advisor

World Health Organization

Bonn, Germany

\section{Thomas Lambert}

Environmental Health Data Analyst

New Hampshire Department of Health and Human Services

Concord, $\mathrm{NH}$

\section{Sam LeFevre}

Program Manager

Environmental Epidemiology Program, Utah Department of Health

Salt Lake City, UT

Jonathan Levy

Associate Professor of Environmental Health and Risk Assessment

Harvard School of Public Health Department of Environmental Health

Boston, MA

Thomas Louis (Work group chair)

Professor

Department of Biostatistics

Johns Hopkins Bloomberg School of Public Health

Baltimore, MD

\section{Helene Margolis}

Epidemiologist

California Department of Public Health

Sacramento, CA

Thomas Matte (Steering committee member)

Medical Epidemiologist

US Centers for Disease Control and Prevention

\section{Sylvia Medina}

Coordinator of European Projects

Institut de Veille Sanitaire (InVS) Department of Environmental Health

Saint Maurice, France

\section{Orrin Myers}

Department of Internal Medicine

University of New Mexico

Albuquerque, NM

\section{Clifford S. Mitchell}

Director of Environmental Health Coordination Program Maryland Department of Health and Mental Hygiene

Baltimore, MD

\section{Lucas Neas}

Acting Chief, Epidemiology and Biomarkers Branch US Environmental Protection Agency

Chapel Hill, NC

\section{Robert O'Keefe}

Vice President

Health Effects Institute

Boston, MA

\section{Chris Paulu}

Epidemiologist

State of Maine

Augusta, ME

Judy Rager

Research Specialist

University of Pittsburgh

Graduate School of Public Health

Pittsburgh, PA

\section{Eric Roberts}

Director Health Surveillance

California Environmental Health Tracking Program

Richmond, CA

\section{Margaret Round}

Environmental Analyst

Massachusetts Department of Public Health

Bureau of Environmental Health

Boston, MA 
Jonathan Samet (Steering committee member; Steering committee chair)

Professor and Chair

Department of Epidemiology

Johns Hopkins Bloomberg School of Public Health

Baltimore, MD

Jeremy Sarnat (Steering committee member; Work group rapporteur)

Assistant Professor of Environmental and Occupational Health

Emory University School of Public Health

and US Centers for Disease Control and Prevention

Atlanta GA

\section{Susan Stone}

Environmental Health Scientist

US Environmental Protection Agency

Research Triangle Park, NC

\section{Thomas Talbot}

Chief

Environmental Health Surveillance Section

New York State Department of Health

Troy, NY

\section{Evelyn Talbott}

Professor

University of Pittsburgh

Graduate School of Public Health Department of Epidemiology

Pittsburgh, PA

\section{Annemoon van Erp}

Senior Scientist

Health Effects Institute

Boston, MA

\section{Daniel Wartenberg}

Professor

Department of Environmental and Occupational Medicine University of Medicine and Dentistry of New Jersey

Piscataway, NJ

\section{Warren White}

Atmospheric Mathematician

Crocker Nuclear Laboratory

University of California

Davis, CA
Fuyuen Yip (Steering committee member; Work group rapporteur)

Epidemiologist

Centers for Disease Control and Prevention

National Center for Environmental Health Air Pollution and Respiratory Health Branch

Atlanta, GA

\section{References}

Bachmann J (2008) Air pollution forecasts and results-oriented tracking. Air Qual Atmos Health 1(4):203-207. doi:10.1007/s11869-0080025-8

Boothe V, Dimmick WF, Talbot TO (2005) Relating air quality and environmental public health tracking data. In: Aral MM, Sinks T (Eds) Environmental exposure and health. Ecol Environ 85:43-52

Brunekreef B, Miller BG, Hurley JF (2007) The brave new world of lives sacrificed and saved, deaths attributed and avoided. Epidemiol 18:785-788

Burnett RT, Bartlett S, Jessiman B et al (2005) Measuring progress in the management of ambient air quality: the case for population health. J Toxicol Environ Health, Part A 68:1289-1300

Centers for Disease Control and Prevention (2006) CDC's National Environmental Public Health Tracking Program: National Network Implementation Plan (NNIP). Available at: http://www.cdc. gov/nceh/tracking/pdfs/nnip.pdf

Cohen AJ, Anderson HR, Ostro B, Pandey KD, Krzyzanowski M, Kuenzli N, Gutschmidt K, Pope CA, Romieu I, Samet JM, Smith KR (2004) Mortality impacts of urban air pollution. In: Ezzati M, Lopez AD, Rodgers A, Murray CJL (eds) Comparative quantification of health risks: global and regional burden of disease due to selected major risk factors, vol 2. World Health Organization, Geneva

Environmental Health Tracking Project Team (2000) America's environmental health gap: why the country needs a nationwide health tracking network. http://healthyamericans.org/reports/files/ healthgap.pdf

Frumkin H, Frank L, Jackson R (2004) Urban sprawl and public health. Island Press, Washington

Fuentes M (2009) Statistical issues in health impact assessment at the state and local levels. Air Qual Atmos Health 2(1):47-55. doi:10.1007/s11869-009-0033-3

HEI Accountability Working Group (2003) Assessing health impact of air quality regulations: concepts and methods for accountability research. communication 11. Health Effects Institute, Boston

Hubbell B, Fann N, Levy JI (2009) Methodological considerations in developing local scale health impact assessments: balancing national, regional, and local data. Air Qual Atmos Health 2(2):99110. doi: $10.1007 / \mathrm{s} 11869-009-0037-\mathrm{Z}$

Intergovernmental Panel on Climate Change (2005) Guidance notes for lead authors of the IPCC Fourth Assessment Report on Addressing Uncertainties. Available at: http://www.ipcc.ch/pdf/ assessment-report/ar4/wg1/ar4-uncertaintyguidancenote.pdf. Accessed 4/1/08

Jerrett M, Burnett RT, Ma R, Pope CA 3rd, Krewski D, Newbold KB, Thurston G, Shi Y, Finkelstein N, Calle EE, Thun MJ (2005) Spatial analysis of air pollution and mortality in Los Angeles. Epidemiology 16(6):727-736

Katsouyanni K, Touloumi G, Samoli E et al (2001) Confounding and effect modification in the short-term effects of ambient particles 
on total mortality: results from 29 European cities within the APHEA2 project. Epidemiol 12(5):521-531

Le Tertre A, Schwartz J, Touloumi G (2005) Empirical Bayes and adjusted estimates approach to estimating the relation of mortality to exposure to PM10. Risk Anal 25:711-718

McMichael AJ, Anderson HR, Brunekreef B, Cohen AJ (1998) Inappropriate use of daily mortality analyses to estimate longerterm mortality effects of air pollution. Int J Epidemiol 27:450-453

Medina S, Le Tertre A, Sklad M (2009) The APHEIS Project: air pollution and health - a European information system. Air Qual Atmos Health 2(4) (this issue). doi:10.1007/s11869-009-0050-2

Meyer P, Watkins T, Qualters J (2006) Establishing a national environmental public health tracking network. Air and Waste Management Association, Pittsburgh, pp 22-24

Miller KA, Siscovick DS, Sheppard L, Shepherd K, Sullivan JH, Anderson GL, Kaufman JD (2007) Long-term exposure to air pollution and incidence of cardiovascular events in women. $\mathrm{N}$ Engl J Med 356(5):447-458

Rabl A (2005) Air pollution mortality: harvesting and loss of life expectancy. J Toxicol Environ Health Part A 68:1175-1180

Samet JM, Zeger SL, Dominici F, Curriero F, Corsac I, Dockery DM, Schwartz J, Zanobetti A (2000) The national morbidity, mortality, and air pollution study, part II: morbidity and mortality from air pollution in the United States. Research Report 94. Health Effects Institute, Cambridge

Samet JM (2008) (2008) Air pollution risk estimates: determinants of heterogeneity. J Toxicol Environ Health A 71:578-582

Shin HH, Stieb DM, Jessiman B, Goldberg MS, Brion O, Brook J, Ramsay T, Burnett RT (2009) Measuring public health accountability of air quality management. Air Qual Atmos Health 2 (1):11-20. doi:10.1007/s11869-009-0029-Z

Talbot TO, Strand M, Vedal S, Rodes C, Dutton SJ, Gelfand EW, Rabinovitch N, Haley VB, Dimmick WF, Paulu C, Talbott EO, Rager E (2009) Developing consistent data and methods to measure the public health impacts of ambient air quality for environmental public health tracking: progress to date and future directions. Air Qual Atmos Health 2(4) (this issue). doi:10.1007/s11869-009-0043-1

Thacker SB, Berkelman RL (1988) Public health surveillance in the United States. Epidemiol Rev 10:164-190
US Environmental Protection Agency (1997) The benefits and costs of the Clean Air Act: 1970 to 1990. Office of Air and Radiation/ Office of Policy, Washington

US Environmental Protection Agency (1999) The benefits and costs of the Clean Air Act: 1990 to 2010. Office of Air and Radiation/ Office of Policy, Washington

US Environmental Protection Agency (2004a) Air quality criteria for particulate matter (October 2004). Washington, DC, EPA 600/P99/002aF-bF

US Environmental Protection Agency (2004b) Final regulatory analysis: control of emissions from nonroad diesel engines. EPA420-R-04-007. Prepared by the Office of Air and Radiation. Available at: http://www.epa.gov/nonroad-diesel/2004fr/ 420r04007.pdf

US Environmental Protection Agency (2005a) Regulatory impact analysis for the clean air interstate rule. EPA 452/-03-001. Prepared by the Office of Air and Radiation. Available at: http://www.epa.gov/cair/pdfs/finaltech08.pdf

US Environmental Protection Agency (2005b) Particulate matter health risk assessment for selected urban areas. December 2005, EPA 452/R-05-007A

US Environmental Protection Agency (2006) Air quality criteria for ozone and related photochemical oxidants (Final). US Environmental Protection Agency, Washington, DC, EPA/600/R-05/ $004 \mathrm{aF}-\mathrm{cF}$

US Environmental Protection Agency (2007) Regulatory impact analysis of the proposed revisions to the national ambient air quality standards for ground-level ozone. Office of Air Quality Planning and Standards, EPA-452/R-07-008

US Environmental Protection Agency (2008) National air quality status and trends through 2007. Office of Air Quality Planning and Standards, Research Triangle Park, North Carolina, EPA454/R-08-006

Wartenberg D (2009) Communicating air quality health impact estimates and their limitations to stakeholders. Air Qual Atmos Health 2(4) (this issue). doi:10.1007/s11869-009-0046-y

White W (2009) Considerations in the use of ozone and $\mathrm{PM}_{2.5}$ data in exposure assessment. Air Qual Atmos Health 2(4) (this issue). doi:10.1007/s11869-009-0056-9 